\title{
Measurement of Converting Enzyme Activity by Antibody-Trapping of Generated Angiotensin II Comparison With Two Other Methods
}

Jürg Nussberger, Dorette Brunner, Irène Keller, and Hans R. Brunner

Activity of the angiotensin converting enzyme (ACE) is usually measured in vitro by estimation of products cleaved by the enzyme from synthetic substrates. These substrates have affinities for ACE different from the natural substrate angiotensin $I$, and insensitive detection systems necessitate millimolar substrate concentrations while physiological angiotensin I concentrations are in the picomolar range.

A new assay for ACE activity measurement was developed which reliably quantitates femtomoles of generated angiotensin II in plasma from angiotensin $\mathrm{I}$ added at a $17 \mathrm{pmol} / \mathrm{mL}$ concentration. The production of high affinity monoclonal antibodies against angiotensin II $\left(K_{d}=7 \times 10^{-11} \mathrm{~mol} / \mathrm{L}\right)$ allowed a quantitative trapping (and thus protection from degrading enzymes) of angiotensin II generated during the incubation step and subsequent radioimmunoassay by simple dilution with labelled angiotensin II.

Using $40 \mu \mathrm{L}$ plasma, the detection limit was 20 $\mathrm{fmol} / \mathrm{mL} / \mathrm{min}$. Normal human plasma has an ACE activity of $335 \pm 83 \mathrm{fmol} / \mathrm{mL} / \mathrm{min}$ (mean $\pm \mathrm{SD}$ ). Precision was characterized by coefficients of variation of $\leq 11 \%$ both within-assay and betweenassays. Accuracy of the new method was established by comparing ACE activity with the ratio of plasma angiotensin II/angiotensin I in plasma obtained from normal volunteers 0.5 to $24 \mathrm{~h}$ after oral administration of $20 \mathrm{mg}$ enalapril. The percentage of ACE inhibition indicated by both methods was almost identical $(\mathrm{r}=0.93, \mathrm{n}=60, P<.001)$. Since the latter ratio appears to reflect in vivo $A C E$ activity, these results indicate that accurate measurement in vitro of ACE activity in vivo has been achieved. Am J Hypertens 1992;5:393-398

KEY WORDS: Angiotensin converting enzyme inhibition, antibody-trapping assay, monoclonal antibodies, plasma angiotensin II/angiotensin I ratio, enalapril, accuracy, precision.
I $\mathrm{n}$ vitro measurement of the enzyme activity of angiotensin converting enzyme (ACE) in plasma and other biological samples is based on cleavage of synthetic substrates by the ACE. Products cleaved from these substrates under standardized reaction conditions are quantitated in order to estimate ACE

Received February 4, 1991. Accepted December 10, 1991.

From the Division of Hypertension, University Hospital, Lausanne, Switzerland.

Address correspondence and reprint requests to Jürg Nussberger, MD, Division of Hypertension, CHUV, 1011 Lausanne, Switzerland. activity. ${ }^{1-3}$ Over the last two decades, ACE inhibiting drugs became available and today are widely used for the treatment of hypertension and congestive heart failure. Plasma ACE activity is measured for drug monitoring in patients treated with ACE inhibitors and the conventional methods used so far provided well-reproducible results. However, in contrast to such consistency in measurement (precision), absolute ACE activities were found to differ considerably (accuracy) when measured in a given plasma with different methods. ${ }^{4}$ Moreover, while the ratio of plasma concentrations of 
angiotensin (Ang) II to AngI can always be used as an indicator of ACE activity in vivo, 5,6 different methods of $\mathrm{ACE}$ activity measurement must be applied in vitro depending on which particular ACE inhibitor is monitored. This is necessary to obtain the appropriate parallelism between results in vivo and in vitro. ${ }^{4}$ The inaccuracy of conventional methods may be caused by several factors: first, the substrates used are chemically different from the natural substrate angiotensin I; second, the insensitive detection systems used to quantitate products cleaved by ACE from these substrates necessitate very high substrate concentrations (millimolar); and third, the dilution of biological samples in vitro induces reaction conditions that are different from those in vivo.

The present paper introduces a new and accurate method of measurement of ACE activity that overcomes the above-mentioned difficulties. Plasma ACE activity is estimated in minimally diluted specimens, using the

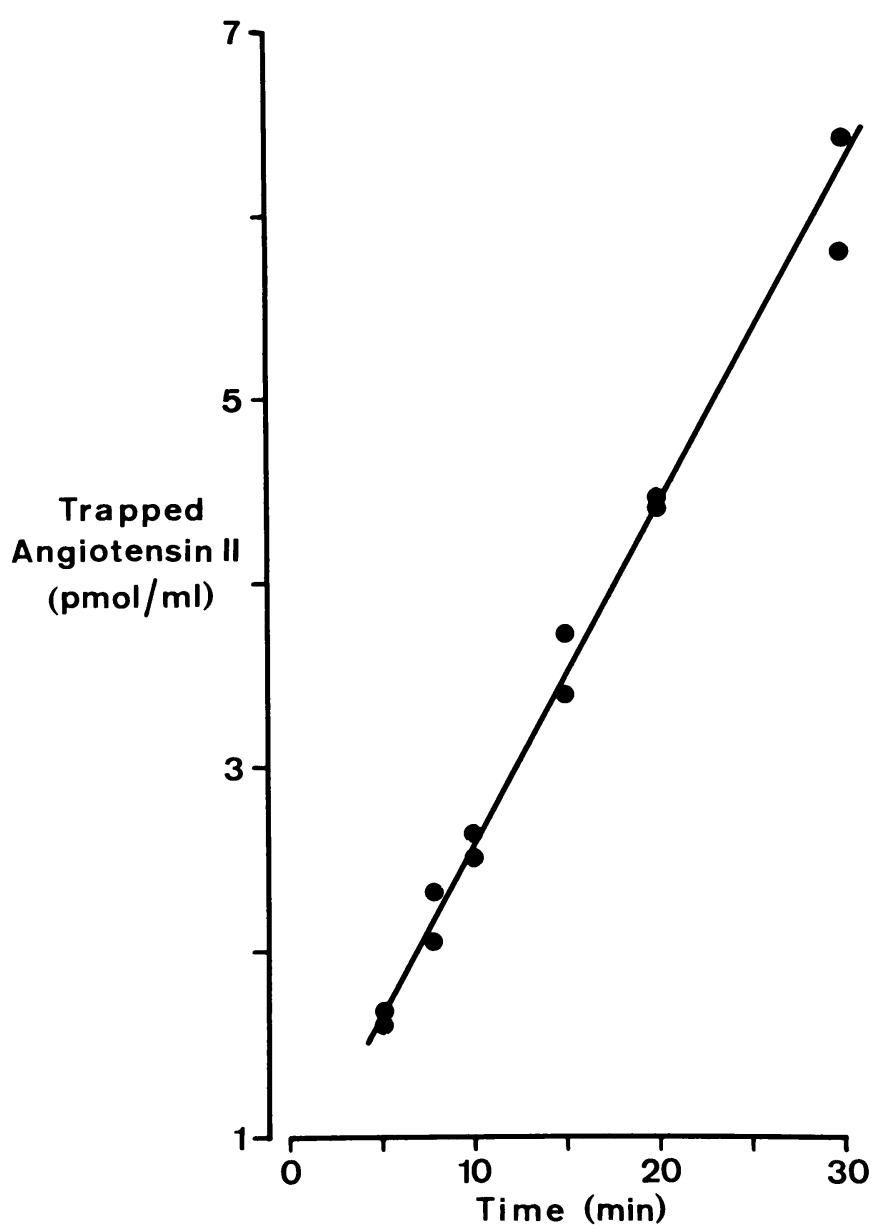

FIGURE 1. Linearity of generation of angiotensin II in a plasma sample incubated at $37^{\circ} \mathrm{C}$ : generated angiotensin II is trapped by added high affinity monoclonal antibodies and protected against enzymatic degradation. Subsequent dilution makes it possible to quantitate angiotensin II radioimmunologically by using these antibodies. natural substrate angiotensin I at low nanomolar concentration. (For comparison, note that endogenous plasma angiotensin I levels may reach high picomolar concentrations after ACE inhibition). Femtomoles of generated angiotensin II are trapped by specific high affinity monoclonal antibodies and thus protected from degradation by angiotensinases during the incubation step. The same antibodies are subsequently used for quantitation by radioimmunoassay. ${ }^{7}$

\section{METHODS}

Study Protocol Ten normal human volunteers aged 20 to 28 years (body weight 63 to $85 \mathrm{~kg}$ ) participated in the study. On the study day, they came to the hospital at 7 $\mathrm{AM}$ and were installed in the supine position. At $8 \mathrm{AM}$, the subjects ingested $20 \mathrm{mg}$ enalapril, an inhibitor of angiotensin converting enzyme. Venous blood samples were collected before (time 0 ) and at $0.5,1,2,4,8$, and $24 \mathrm{~h}$ after enalapril intake. Subjects remained in the supine position for $1 \mathrm{~h}$ prior to blood sampling and no food intake was permitted for the $3 \mathrm{~h}$ prior to sampling.

Blood Sampling For the measurement of ACE activity, blood samples $(5 \mathrm{~mL})$ were collected from the antecubital vein into prechilled glass tubes containing heparin (56 USP) and $25 \mu \mathrm{L}$ renin inhibitor CGP 29287 (CibaGeigy, Basel, Switzerland) at a concentration of $1 \mathrm{mmol} / \mathrm{L}$ water. Blood was centrifuged at $4^{\circ} \mathrm{C}$ and $2000 \mathrm{~g}$ for $10 \mathrm{~min}$ and plasma aliquots of $0.5 \mathrm{~mL}$ were snap frozen in liquid nitrogen and stored at $-70^{\circ} \mathrm{C}$ until analyzed.

For the measurement of Ang $\mathrm{II}^{8}$ and immunoreactive Ang I, ${ }^{9}$ another $10 \mathrm{~mL}$ blood were collected on an inhibitor cocktail containing EDTA and renin inhibitor to prevent degradation and generation of these peptides in vitro. Samples were centrifuged at $4^{\circ} \mathrm{C}$ and plasma aliquots of $2.2 \mathrm{~mL}$ snap frozen and stored as described above.

Material Monoclonal antibodies against angiotensin II were produced by the somatic cell fusion technique ${ }^{10}$ as previously described in detail. ${ }^{11}$ However, we used SP $2 / 0$ myeloma cells and spleen lymphocytes of a C3H mouse hyperimmunized with Ang II coupled to bovine thyroglobulin. ${ }^{12}$ For the measurement of ACE activity, a high-affinity monoclonal angiotensin II antibody $\left(\mathrm{K}_{\mathrm{d}}=\right.$ $7 \times 10^{-11} \mathrm{~mol} / \mathrm{L}$ ) of the IgG1 class was used which cross-reacted with the carboxyterminal fragments of Ang II at 75 to $105 \%$ and less than $1 \%$ with Ang I and aminoterminal fragments. No cross-reaction (below $10^{-6} \%$ ) was found with angiotensinase inhibitors such as tripotassium ethylenediaminetetraacetate (EDTA, purchased from Fluka, Buchs, Switzerland) or bacitracin (Grossman Pharmaca, Basel, Switzerland).

The albumin buffer consisted of a $0.1 \mathrm{~mol} / \mathrm{L}$ Tris buffer (Sigma, St. Louis, MO) containing $5 \mathrm{~g} / \mathrm{L}$ heat-inactivated bovine serum albumin (Sigma), $20 \mathrm{mmol} / \mathrm{L}$ 
TABLE 1. PLASMA CONVERTING ENZYME ACTIVITY AND ANGIOTENSIN CONCENTRATIONS IN HEALTHY HUMANS AFTER A SINGLE ORAL DOSE OF $20 \mathrm{mg}$ ENALAPRIL (MEAN $\pm S E M, n=10$ )

\begin{tabular}{cccccc}
\hline $\begin{array}{c}\text { Time After } \\
\text { Enalapril } \\
\text { Intake (h) }\end{array}$ & $\begin{array}{c}\text { ACE Activity } \\
\text { Trapping Assay } \\
\text { (fmol/mL/min) }\end{array}$ & $\begin{array}{c}\text { ACE Activity } \\
\text { Conventional Assay } \\
\text { (nmol/mL/min) }\end{array}$ & $\begin{array}{c}\text { Angiotensin I } \\
\text { (fmol/mL) }\end{array}$ & $\begin{array}{c}\text { Angiotensin II } \\
\text { (fmol/mL) }\end{array}$ & $\begin{array}{c}\text { Ang II/Ang I } \\
\text { Ratio }\end{array}$ \\
\hline 0 & $335 \pm 28$ & $18.0 \pm 1.6$ & $8.2 \pm 1.7$ & $5.2 \pm 0.6$ & $0.780 \pm 0.120$ \\
0.5 & $295 \pm 27$ & $18.1 \pm 1.7$ & $7.3 \pm 1.5$ & $4.6 \pm 0.5$ & $0.748 \pm 0.101$ \\
1 & $107 \pm 17$ & $12.1 \pm 1.2$ & $13.5 \pm 3.0$ & $2.9 \pm 0.5$ & $0.315 \pm 0.094$ \\
2 & $28 \pm 8$ & $4.5 \pm 0.8$ & $45.7 \pm 12.9$ & $1.1 \pm 0.3$ & $0.029 \pm 0.006$ \\
4 & $15 \pm 10$ & $3.0 \pm 0.4$ & $66.8 \pm 17.6$ & $1.0 \pm 0.2$ & $0.015 \pm 0.003$ \\
8 & $5 \pm 5$ & $3.7 \pm 0.4$ & $76.6 \pm 15.9$ & $1.6 \pm 0.4$ & $0.016 \pm 0.003$ \\
24 & $87 \pm 10$ & $11.2 \pm 1.0$ & $32.1 \pm 6.4$ & $3.8 \pm 0.5$ & $0.147 \pm 0.027$ \\
\hline
\end{tabular}

bacitracin, and $200 \mathrm{mg} / \mathrm{L}$ sodium azide (Merck, Darmstadt, Germany). The $\mathrm{pH}$ was adjusted to 7.5 at room temperature. Angiotensin I and angiotensin II standard peptides were purchased from Peninsula Labs (St. Helens, Merseyside, England). ${ }^{125} \mathrm{I}$-Ang II was obtained from New England Nuclear Inc. (Boston, MA).

Measurement of Plasma ACE Activity All procedures were done in an ice-water bath unless stated otherwise. Plasma was thawed and centrifuged at $4^{\circ} \mathrm{C}$ and $40 \mu \mathrm{L}$ supernatant was pipetted into a small polypropylene tube. We added $10 \mu \mathrm{L}$ monoclonal antibody (mouse ascites diluted 1:8400 in $3 \mathrm{~mol} / \mathrm{L}$ Tris buffer at $\mathrm{pH}$ 7.3). We added $1 \mathrm{pmol}$ angiotensin I in $10 \mu \mathrm{L}$ albumin buffer. For blank determination, a duplicate $40 \mu \mathrm{L}$ plasma sample was processed identically, but the albumin buffer contained in addition to angiotensin I also EDTA at a $0.2 \mathrm{~mol} / \mathrm{L}$ concentration. After mixing and cold centrifugation in order to concentrate the mixture at the bottom of the tube ( $1 \mathrm{~min}$ at $2000 \mathrm{~g}$ ) samples were incubated in a water bath at $37^{\circ} \mathrm{C}$ for $20 \mathrm{~min}$. Incubation was stopped by returning the samples to the icewater bath. We added $40 \mu \mathrm{L}$ albumin buffer without/ with $0.05 \mathrm{~mol} / \mathrm{L}$ EDTA to blanks/samples in order to equalize conditions. Each tube (total $100 \mu \mathrm{L}$ ) finally received $1 \mathrm{~mL}$ albumin buffer containing $1 \mathrm{fmol}{ }^{125} \mathrm{I}$-Ang II (2000 counts/minute) and EDTA at $0.02 \mathrm{~mol} / \mathrm{L}$ concentration. After a $24 \mathrm{~h}$ incubation at $4^{\circ} \mathrm{C}$, antibodybound and free Ang II were separated by adding $0.3 \mathrm{~mL}$ water containing $2 \%$ dextran-coated charcoal, mixing for $10 \mathrm{~min}$, centrifuging at $4^{\circ} \mathrm{C}$ (for $20 \mathrm{~min}$ at $6000 \mathrm{~g}$ ), and decanting the supernatant. Supernatant and pellet were counted in a ten-well scintillation counter (Gammamaster, Wallac, Turku, Finland) and generated Ang II was read from a simultaneously established standard curve.

For the standard curve, increasing amounts of unlabelled Ang II ranging from 16 to $4000 \mathrm{fmol}$ in $40 \mu \mathrm{L}$ albumin buffer were added to $40 \mu \mathrm{L}$ pooled plasma that contained unmeasurably low endogenous Ang I and Ang II and renin inhibitor CGP 29287 at a $0.01 \mathrm{mmol} / \mathrm{L}$ concentration; we added antibody in a $3 \mathrm{~mol} / \mathrm{L}$ Tris buffer $(10 \mu \mathrm{L})$ and $1000 \mathrm{fmol}$ Ang I in EDTA-albumin buffer $(10 \mu \mathrm{L})$ in order to obtain conditions identical to the unknown samples. Plasma ACE activity was also measured by an established method using as substrate synthetic carbobenzoxy-Phe-His-Leu at $1.8 \mathrm{mmol} / \mathrm{L}$ concentration..$^{3,4}$ The ratio of the plasma concentrations Ang II/Ang I was used for estimation of ACE activity "in vivo".6

\section{RESULTS}

Characteristics of Trapping-Assay for Plasma ACE Activity Sensitivity The present assay is optimized for a final dilution of the monoclonal antibody at $1: 924,000$. The smallest amount of unlabelled Ang II (16 fmol/tube) added to the standard curve results in antibody-binding of $50 \%$ of the tracer angiotensin. This is more than two standard deviations less than tracer binding in the absence of unlabelled Ang II. Thus, the smallest possible amount of Ang II that can be read from the standard slope is $16 \mathrm{fmol}$. The theoretical detection limit for ACE activity in a $40 \mu \mathrm{L}$ plasma sample that was incubated for $20 \mathrm{~min}$ at $37^{\circ} \mathrm{C}$ is $20 \mathrm{fmol} / \mathrm{mL} / \mathrm{min}$ $(16 \times 25 / 20)$. The actual detection limit is zero, since EDTA-blanks may contain more than $16 \mathrm{fmol} \mathrm{Ang} \mathrm{II}$ and these blanks are subtracted from Ang II generated during the incubation.

Specificity ACE is a relative unspecific enzyme since it cleaves substrates other than Ang I, such as bradykinin or substance $\mathrm{P}$. The present assay measures specifically Ang II (carboxyterminal-specific monoclonal antibody) and uses Ang I as substrate under conditions in vitro approaching those found in vivo. Endogenous Ang II is subtracted as well as Ang II generated in plasma despite renin inhibition and ACE inhibition by EDTA (blanks).

Precision Within-assay precision was determined by repeated measurement within a single assay of plasma aliquots containing low, intermediate, or high ACE activity $(\mathrm{n}=10 \mathrm{each})$. The results were (mean $\pm \mathrm{SD}$ ) $87.3 \pm 9.4 \mathrm{fmol} / \mathrm{mL} / \mathrm{min}, 144.9 \pm 9.2 \mathrm{fmol} / \mathrm{mL} / \mathrm{min}$, $205.5 \pm 13.9 \mathrm{fmol} / \mathrm{mL} / \mathrm{min}$, and $389.0 \pm 21.3 \mathrm{fmol} /$ $\mathrm{mL} / \mathrm{min}$, respectively. The corresponding coefficients 

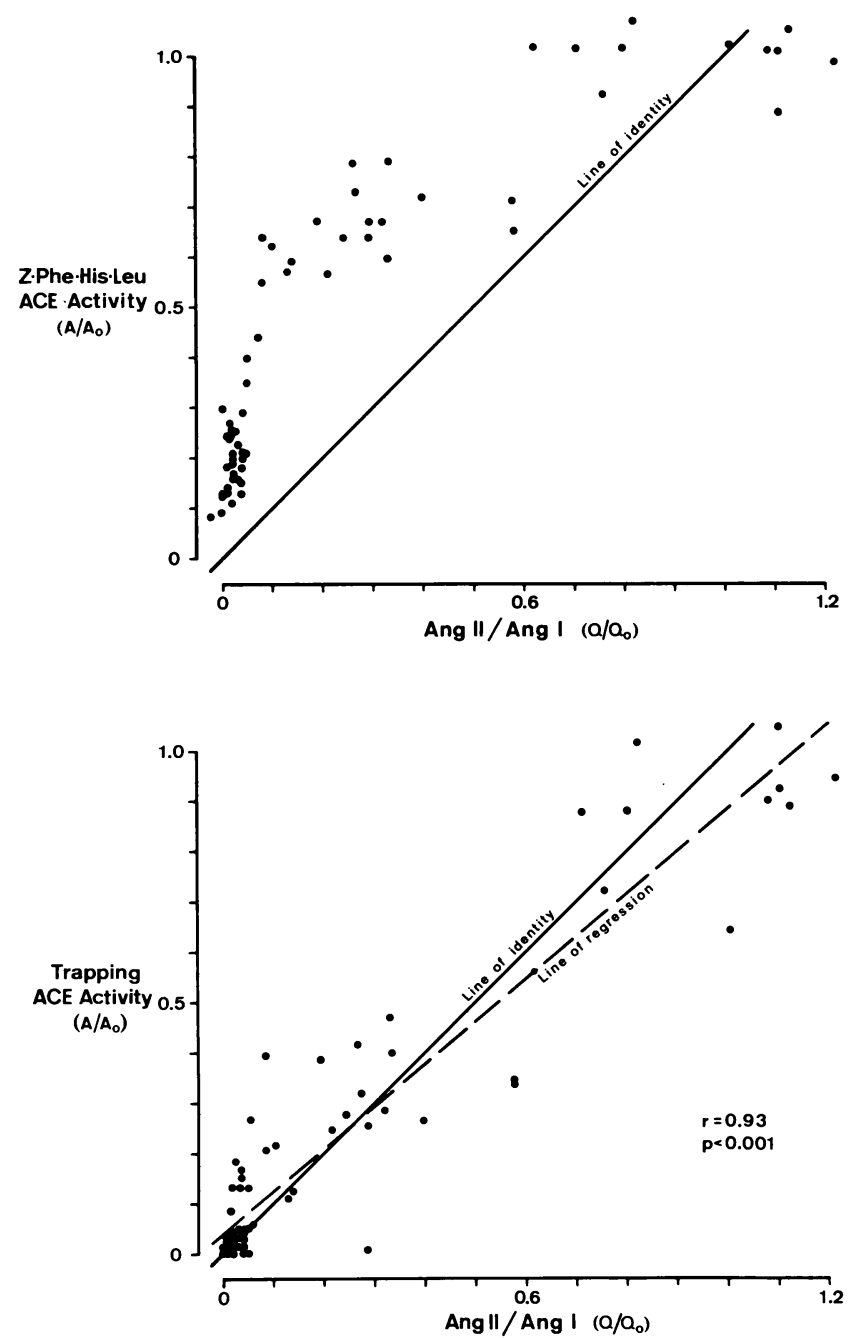

FIGURE 2. Assessment of converting enzyme (ACE) inhibition in vitro (ordinate) and in vivo (Ang II/Ang I): ACE activity in the plasma of 10 normal men up to $24 \mathrm{~h}$ after ingestion of $20 \mathrm{mg}$ enalapril $(n=60)$. In vitro measurement by conventional procedure using carbobenzoxy-Phe-His-Leu (Z-Phe-His-Leu) as substrate (upper panel) underestimated ACE inhibition, whereas the new trapping method (lower panel) indicated similar ACE activity in vitro $(A)$ as estimated in vivo $(Q)$ by the ratio of plasma angiotensin II to angiotensin I. Plasma ACE activity before enalapril ingestion is $A_{o}$ in vitro and $Q_{o}$ in vivo.

of variation (CV) for within-assay precision were $10.8 \%, 6.4 \%, 6.8 \%$, and $5.5 \%$. Similarly, a plasma was analyzed on 24 different days and it was found to contain an ACE activity of $228.6 \pm 24.9 \mathrm{fmol} / \mathrm{mL} / \mathrm{min}$, ie, a CV for between-assay precision of $10.9 \%$.

Normal Values Plasma ACE activity in 22 normal human subjects was found to be $334.7 \pm 82.9 \mathrm{fmol} /$ $\mathrm{mL} / \mathrm{min}$ (mean $\pm \mathrm{SD}$ ) with a range between 178 and 475 .
Linearity The linearity of the enzymatic reaction during incubation at $37^{\circ} \mathrm{C}$ was tested by incubating a normal plasma sample for $5,8,10,15,20$, and $30 \mathrm{~min}$ at $37^{\circ} \mathrm{C}$. Results are shown in Figure 1: there was a good linearity throughout the entire test period.

Accuracy of Trapping Assay Table 1 shows the effect of a single oral dose of $20 \mathrm{mg}$ enalapril in 10 volunteers on plasma ACE activity, plasma levels of Ang I and Ang II, and the ratio of plasma Ang II to Ang I. All parameters reached peak effects at 4 and $8 \mathrm{~h}$ after enalapril administration. The ACE results obtained with the trapping method were well correlated with those obtained by the conventional method $(\mathrm{r}=0.95, P<.001)$. Conventionally measured ACE activity was related to but different from the plasma angiotensin II/angiotensin I ratio (Figure 2, upper panel). In contrast, the results of the trapping method $(y)$ - unlike conventionally obtained results - are virtually identical with ACE activity in vivo $(\mathrm{x}): \mathrm{y}=0.82 \mathrm{x}+4.64$ (Figure 2, lower panel).

Measured ACE activities were expressed for every subject as a percent of baseline ACE activity and means $\pm S E M$ were calculated for each time point (Figure 3 ). In vivo ACE activity (ratio of plasma Ang II to Ang I) reached minima at 4 and $8 \mathrm{~h}$ after enalapril intake of $2.1 \pm 0.3$ and $2.0 \pm 0.4 \%$. On the following morning $(24 \mathrm{~h})$ in vivo ACE activity was still only $21.9 \pm 5.0 \%$. This was in excellent agreement with ACE activities measured in vitro with the trapping assay: $3.6 \pm 2.4$, $1.3 \pm 1.3$, and $27.4 \pm 3.4 \%$. In contrast, the conventional method for ACE activity measurement in vitro provided different results: at 4,8 , and $24 \mathrm{~h}$ after enalapril administration, plasma ACE activities were found to be at $16.5 \pm 1.7,20.8 \pm 1.7$ and $62.6 \pm 1.6 \%$ of pretreatment values.

\section{DISCUSSION}

Accuracy of test results is a key issue for comparing the biochemical effects of different drugs of the same class of therapeutic agents. Most studies involving ACE inhibitors so far were endorsed by the established measurement of plasma ACE activity using a high concentration of substrates with more or less affinity for the ACE. ${ }^{1-3}$ Recently, studies comparing the effects of different ACE inhibitors in normal volunteers provided evidence for the clear dependency of results on methods used for ACE measurement and the need for reliable measurement of plasma angiotensin I and II has been emphasized. ${ }^{4,6}$ Therefore an assay was developed which could accurately reflect ACE activity (and ACE inhibition) as found in the living organism and which would allow us to compare the efficacy of different ACE inhibitors. The present paper confirms our hypothesis that $A C E$ activity 


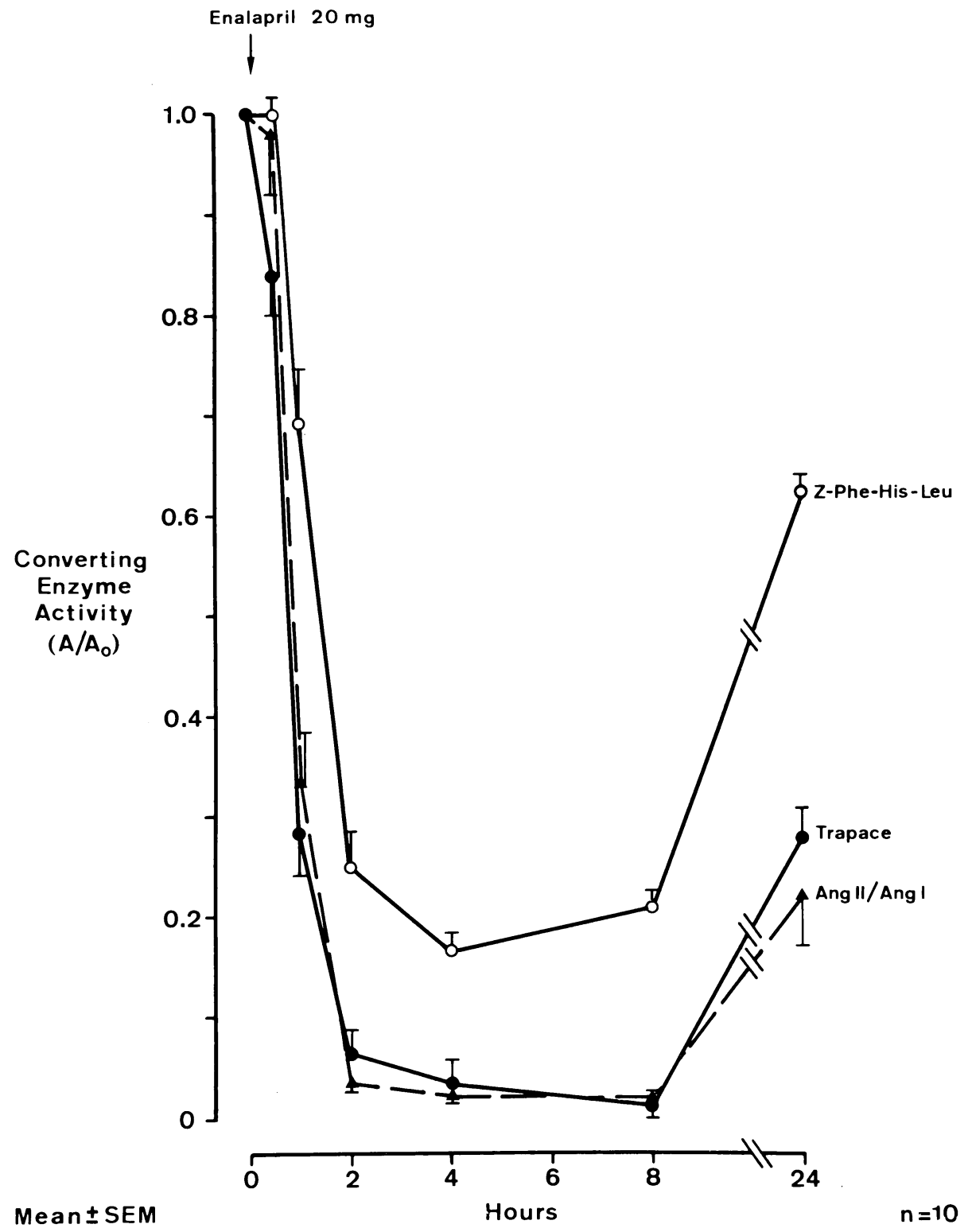

FIGURE 3. In vivo (dashed line) and in vitro (solid lines) plasma converting enzyme ( $A C E)$ activity in 10 normal men before and up to $24 \mathrm{~h}$ after ingestion of $20 \mathrm{mg}$ enalapril. In vivo ACE activity was estimated by the ratio of plasma angiotensin II to angiotensin I (Ang II/Ang I). In vitro measurement using the new trapping assay (Trapace, filled circles) gave virtually identical results as those measured in vivo. Conventional measurement of ACE activity in vitro using the substrate carbobenzoxy-PheHis-Leu (Z-Phe-His-Leu, open circles) underestimated ACE inhibition.

measured in vitro under more "physiological" conditions is virtually identical with ACE activity in vivo.

In our volunteers, the ratio of plasma Ang II and Ang I was used to estimate in vivo ACE activity. Activity decreased by $98 \%$ at peak inhibition and returned to $22 \%$ ACE activity at $24 \mathrm{~h}$. Very similar results were obtained for plasma ACE activity measured in vitro with the new method based on trapping by monoclonal antibodies of generated Ang II (decrease by $99 \%$ at peak inhibition and return to $27 \% \mathrm{ACE}$ activity at $24 \mathrm{~h}$ ). In contrast, the conventional method of ACE activity estimation provided different results: peak ACE inhibition with only $83 \%$ decrease from baseline and a substantial return towards baseline with $66 \%$ ACE activity at $24 \mathrm{~h}$. Thus, the new method of ACE activity measurement provided more accurate results than the established method, if the ratio of plasma Ang II/Ang I is accepted as a standard. Our results were obtained in subjects treated with enalapril. Further experience must now be gained with other ACE inhibitors. Changes in endogenous angiotensin I concentration may have different impacts depending on the ACE inhibitor used. The effect of the relationship between plasma and tissue ACE inhibition with different inhibitors remains to be established. If this method were to be adapted for measurement of ACE activity in tissues, serine protease inhibitors would have to be added during the incubation step to prevent angiotensin II generation by enzymes other than ACE.

The new method of ACE activity measurement in vitro compares favorably with established procedures: femtomoles rather than nanomoles can be detected, which may be helpful in comparing the peak effects of 
different ACE inhibitors. The specificity of the procedure is also greatly enhanced since it is based on a monoclonal antibody of unique specificity and affinity for Ang II and the natural substrate Ang I is used under conditions in vitro approaching those found in vivo. In comparison, conventional methods use diluted plasma and extremely high concentrations of substrates with affinities that are different from that of Ang I. Conventional methods may therefore, in the presence of highaffinity ACE inhibitors, lead to underestimation or overestimation of ACE inhibition. The Ang I concentration in almost undiluted plasma of the trapping assay is sufficient to warrant linearity of the Ang II production during the incubation step as demonstrated in Figure 2. The precision of the trapping method is not better than that of the conventional techniques, but coefficients of variation below $11 \%$ for both within- and between-assay precision certainly demonstrate the validity of the new procedure. The high accuracy appears to be a major advantage of the trapping method. Finally, equipment needed for the new procedure is that of a routine radioimmunoassay laboratory including a $\gamma$-counter. Monoclonal antibodies and labelled and unlabelled angiotensins are or will be commercially available.

In conclusion, we have introduced a reliable and accurate new method for the measurement of plasma ACE activity that is based on the trapping of generated Ang II during the enzymatic reaction by high-affinity monoclonal antibodies which are subsequently used to quantitate the peptide by radioimmunoassay.

\section{REFERENCES}

1. Cushman DW, Cheung HS: Concentrations of angiotensin converting enzyme in tissues of the rat. Biochem Biophys Acta 1971;250:261-265.
2. Ryan JW, Chung A, Ammons C, Carlton ML: A simple radioassay for angiotensin-converting enzyme. Biochem J 1977;167:501-504.

3. Piquilloud $Y$, Reinharz A, Roth M: Studies on the angiotensin converting enzyme with different substrates. Biochem Biophys Acta 1970;206:136-142.

4. Juillerat L, Nussberger J, Ménard J, et al: Determinants of angiotensin II generation during converting enzyme inhibition. Hypertension 1990;12:87-92.

5. Giese J, Rasmussen S, Damkjaer MN, Ibsen H: Biochemical monitoring of vasoactive peptides during angiotensin converting enzyme inhibition. J Hypertens 1983;1(suppl 1):31-36.

6. Nussberger J, Juillerat L, Perret F, et al: Need for plasma angiotensin measurements to investigate converting enzyme inhibition in humans. Am Heart J 1989;117:717722.

7. Poulsen $K$, Jörgensen J: An easy radioimmunological microassay of renin activity, concentration and substrate in human and animal plasma and tissues based on angiotensin I trapping by antibody. J Clin Endocrinol Metab 1974;39:816-825.

8. Nussberger J, Brunner DB, Waeber B, Brunner HR: True versus immunoreactive angiotensin II in human plasma. Hypertension 1985;7(suppl I):I1 -I7.

9. Nussberger J, Brunner DB, Waeber B, Brunner HR: In vitro renin inhibition to prevent generation of angiotensins during determination of angiotensin I and II. Life Sci 1988;42:1683-1688.

10. Köhler G, Milstein C: Continuous cultures of fused cells secreting antibody of predefined specificity. Nature 1975;256:495-497.

11. Nussberger J, Mudgett-Hunter M, Matsueda GR, Haber E: A monoclonal antibody specific for the carboxy-terminus of angiotensin II. Hybridoma 1984;3:373-376.

12. Nussberger J, Matsueda GR, Re R, Haber E: Selectivity of angiotensin II antisera. J Immunol Methods 1983;56:8596. 